\title{
THE AWARENESS OF CAREGIVERS ABOUT THEIR CHILDREN'S EXPOSURE TO IONIZING RADIATION ACCOMPANYING MEDICAL PROCEDURES: THE ASSESSMENT STUDY
}

\author{
KATARZYNA JOŃCZYK-POTOCZNA ${ }^{1}$, BEATA PUCHER ${ }^{2}$, LIDIA STRZELCZUK-JUDKA ${ }^{1}$, \\ BEATA BURACZYŃSKA-ANDRZEJEWSKA ${ }^{3}$, BARBARA WIĘCKOWSKA ${ }^{4}$, HANNA KRAUSS ${ }^{3}$, \\ PRZEMYSŁAW BILIŃSKI ${ }^{5}$, and PAULINA WOJTYŁA-BUCIORA ${ }^{3,5}$
}

${ }^{1}$ Poznan University of Medical Sciences, Poznań, Poland

Department of Pediatric Radiology

${ }^{2}$ Poznan University of Medical Sciences, Poznań, Poland

Pediatric ENT Department

${ }^{3}$ Poznan University of Medical Sciences, Poznań, Poland

Department of Physiology

${ }^{4}$ Poznan University of Medical Sciences, Poznań, Poland

Department of Computer Science and Statistics

${ }^{5}$ Higher Vocational State School in Kalisz, Kalisz, Poland

Faculty of Medicine

\begin{abstract}
Objectives: The aim of the study was a survey-based assessment concerning parents of children undergoing CT examinations and their knowledge of detailed information about procedures involved in imaging diagnostics. Material and Methods: A statistical analysis of 108 surveys of parents of children undergoing CT studies in the Department of Pediatric Radiology in Poznań, Poland was done, with the use of Statistica software. Results: In result of the evaluation of all subsections of the substantive question number, the majority of answers were incorrect (68-98\%). No correlation between the number of CT examinations conducted for a child and the number of correct answers to substantive questions was observed. No correlation between the number of CT examinations conducted for a child and the fact of noting the examination with the use of ionizing radiation down in a child's health certificate was stated. The statistical analysis showed that children of parents who declared that the aim of the CT examination had been explained to them better underwent more of them. Conclusions: Parents are poorly informed about a radiation dose and risk related to a CT examination procedure. Int J Occup Med Environ Health. 2019;32(1):65-73
\end{abstract}

Key words:

children, CT examination, parents, radiation protection, ionizing radiation, radiation dose

Received: May 30, 2017. Accepted: May 14, 2018.

Corresponding author: Paulina Wojtyła-Buciora, Poznan University of Medical Sciences, Department of Physiology, Święcickiego 6, 67-781 Poznań, Poland (e-mail: paulinawojtyla@gmail.com). 


\section{INTRODUCTION}

In recent years a significant development of imaging methods using X-ray, which has increased the use of them in everyday clinical practice, could have been observed [1]. This has resulted especially in an increase of using CT for the last 10 years [2]. The era of CT has truly revolutionized the imaging diagnostics, with the technique being right now an acclaimed diagnostic tool in the health care system of both adults and children [3,4]. However, the use of CT has grown mostly in the case of pediatric patients, due to a significant decrease in scan time, eliminating at a great level the necessity of anesthesia required to prevent a child from moving during the examination [3]. Despite its obvious advantages, CT is an examination making use of ionizing radiation, which raises justified concerns about the future increased cancer risk, particularly when the exposition occurs in childhood [2,5]. Children are especially prone to radiation because of higher tissue sensitivity to exposure and longer expected life length, which increases the possibility of radiation effects to occur $[3,6]$. Although CT examinations comprise around $11 \%$ of all radiological procedures, radiation during CT scan delivers around $70 \%$ of medical radiation dose for the USA patients' population [7].

Potential dangerous consequences of CT examination include, among other things, extravasation of contrast dose in a place of vein catheter, fissure of central or peripheral catheter during contrast administration, an allergic reaction to contrast medium and exacerbation of renal insufficiency in children with previous renal dysfunction. In children classified as sensitive a risk of allergic reaction to a non-iodine contrast medium is low, measured 1:10 000$100000[4,8]$. A risk related to a sedation procedure in small children and non-cooperative patients may also be an additional one [4]. A consent for a CT examination should be obtained before sedation or anesthesia. Other risk factors, such as allergic reaction to iodine in medical history, renal diseases, pregnancy are noted down in ques- tionnaires right before examination in most radiological departments [4]. One of the dangers which are not often discussed - because of the lack of awareness of clinicians about radiation dose and its possible effects - is a risk related to exposure to ionizing radiation. Another reason for the lack in discussing this issue might be a problem in informing parents about this complicated topic in an easy, understandable way [4].

Ionizing radiation has a sufficient energy to knock an electron from its orbit, resulting in a creation of ion. In a biological material exposed to ionizing radiation, free hydroxyl radicals, created from interaction of radiation with water particles, are most likely to be formed. The DNA thread exposed to free radicals might be damaged or breached. Possible errors in a process of DNA repair might lead to induction of point mutations, chromosome translocations and gene fusions resulting in multistage development of cancer [3,9]. Moreover, radiation on its own may cause a kind of genetic instability in cells, which increases probability and rapidity of mutation and other genetic changes development after multiple cell division cycles. In addition, in a cytoplasm exposed to radiation, mutation rate is statistically increased. Genetic changes (mutation induction in genome, changes in gene expression) may also be present in newly formed cells which have not been directly exposed to radiation [10].

An effective dose determines a level of the whole body's exposure to radiation even if only certain parts of the body are being exposed to it. Effective doses differ, depending on the diagnostic method in use, a patient's age and time of exposure. Carcinogenesis is a stochastic effect of ionizing radiation: it occurs with a specific probability, which means that it may but does not have to be present. There is no threshold dose of ionizing radiation, at which the process of carcinogenesis might start. However, the bigger exposure dose, the higher probability of carcinogenesis. It should also be indicated that carcinogenesis mostly occurs many years after the exposure to radiation. It is also 
thought that exposure to ionizing radiation at early life stages increases a risk of cancer $[2,5,10,11]$.

So far many research projects concentrating on the level of differently specialized clinicians' knowledge about radiation dose and related risk of later consequences have been conducted. However, the results of them have been unsatisfactory. It seems that a majority of physicians, despite taking classes on protection from radiation, do not have sufficient knowledge about doses of radiation to which patients undergoing broadly used X-ray examinations are exposed [12-15]. Clinicians and physicians alike do not appreciate the amount of radiation dose that is connected with CT examination or related cancer risk [4,7]. This lack of knowledge seems to be especially important when the number of patients undergoing improper or repeated examinations is taken into consideration [12-15].

Patients often poorly understand what is radiological examination associated with, what kind of information it may bring and which potential dangers relate to it [7]. The majority of medical care experts promote a strong need for discussion of both advantages and dangers related to every medical procedure, including diagnostic ones. In order to counteract a rapid growth of CT usage, a proper understanding of dangers related to radiation is crucial [4]. Publications confirming patients' will to obtain information about medical and diagnostic procedures and consents together with a leading physician are already present. They reflect the concept of commonly made decisions [16-18]. Some researchers suggest that parents can contribute to a growing need for CT examinations, while seeking for a quick diagnosis for their children without sufficient knowledge about a potential risk. If these suggestions are true, more detailed and straightforward information about a radiation dose and related risk provided for parents may result in a decrease of need for CT examinations in pediatrics [7,16]. Clinicians and radiologists should provide an objective information about advantages and risks which CT examination encompasses [4].

\section{Objective}

The aim of the study was a survey-based assessment concerning parents of children undergoing CT examinations and their knowledge of detailed information about procedures involved in imaging diagnostics.

\section{MATERIAL AND METHODS}

The authors prepared a survey including a variety of single choice questions which concentrated on CT examination of children (Appendix). The participants, who were the parents, were asked to fill in the forms anonymously and on their own. The survey consisted of 4 sections: the first one included questions about the examination conducted at the moment, a referring unit and undergone hospitalizations and diagnostics. The participants evaluated the suitability of communication with the hospital staff in the second section, while the third one included basic information regarding contributors: social-economic conditions, a place of residence, age and education. Finally, the fourth section consisted of two questions concentrating on parents' awareness of radiation, documentation of a radiation dose and one substantive question. A consent to participate was obtained from all contributors.

The authors analyzed the connection between the number of conducted CT examinations of children and answers to questions that each survey's section consisted of: about explanation of CT examination's aim, harmfulness of ionizing radiation, about the possibility of a consultation with a radiologist, a question related to documentation in a child's health certificate and the request for comparison of radiation dose between chest X-ray and chest CT examination with contrast, head $\mathrm{CT}$ examination with contrast and abdomen and pelvis CT with contrast. The authors studied a correlation between a question related to an explanation of $\mathrm{CT}$ examination procedure and variables: socio-economic conditions, a place of residence, age and education of parents. Similarly, they examined the correlation between questions about explanation of harmful- 
Table 1. Participants in the survey research concerning CT examination of children conducted in 2014-2016 in Poznań, Poland

\begin{tabular}{|c|c|c|}
\hline Characteristics & $\mathrm{n}$ & $\%$ \\
\hline \multicolumn{3}{|l|}{$\begin{array}{l}\text { How do you assess your } \\
\text { socio-economic conditions? }\end{array}$} \\
\hline very good & 20 & 18.519 \\
\hline good & 63 & 58.333 \\
\hline average & 25 & 23.148 \\
\hline \multirow{2}{*}{\multicolumn{3}{|c|}{$\begin{array}{l}\text { Place of residence } \\
\text { city }\end{array}$}} \\
\hline & & \\
\hline$<50000$ inhabitants & 22 & 20.37 \\
\hline $50000-500000$ inhabitants & 19 & 17.593 \\
\hline > 500000 inhabitants & 5 & 4.63 \\
\hline voivodeship city & 14 & 12.963 \\
\hline village & 48 & 44.444 \\
\hline \multicolumn{3}{|l|}{ Parents' age } \\
\hline \multicolumn{3}{|l|}{ mother } \\
\hline $18-29$ years & 11 & 10.185 \\
\hline 30-39 years & 59 & 54.63 \\
\hline 40-49 years & 33 & 30.556 \\
\hline$>50$ years & 5 & 4.63 \\
\hline \multicolumn{3}{|l|}{ father } \\
\hline $18-29$ years & 6 & 5.556 \\
\hline 30-39 years & 39 & 36.111 \\
\hline $40-49$ years & 54 & 50 \\
\hline$>50$ years & 7 & 6.481 \\
\hline lack of data & 2 & 1.852 \\
\hline \multirow{2}{*}{\multicolumn{3}{|c|}{$\begin{array}{l}\text { Parents' education } \\
\text { mother }\end{array}$}} \\
\hline & & \\
\hline lower-secondary & 8 & 7.407 \\
\hline higher & 35 & 32.407 \\
\hline basic vocational & 26 & 24.074 \\
\hline upper-secondary & 39 & 36.111 \\
\hline \multicolumn{3}{|l|}{ father } \\
\hline lower-secondary & 4 & 3.704 \\
\hline higher & 28 & 25.926 \\
\hline basic vocational & 49 & 45.37 \\
\hline upper-secondary & 25 & 23.148 \\
\hline lack of data & 2 & 1.852 \\
\hline
\end{tabular}

ness of CT examination, about the fact of noting down an examination with the use of ionizing radiation in a child's health certificate, about the possibility of consultation with a radiologist as well as between the substantive question and the variables mentioned before. The authors examined the correlation between the number of CT examinations of children and the number of other imaging diagnostic examinations that were conducted (X-ray, USG, MRI, PET) and EEG. The correlation between the type of a referring unit and answers to questions from the survey's sections 2 and 4 was analyzed. The authors compared accuracy of answers to the last question with the number of children's hospitalizations.

The statistical analysis was made by means of the Statistica computer program (version 12). In order to assess normal distribution a Shapiro-Wilk test was used. For the statistical analysis purposes, Mann-Whitney $U$ test and exact Fisher-Freeman-Halton and $\chi^{2} 2 \times 2$ tests, Spearman monotonic function as well as Jonckheere-Terpst's test were used.

\section{RESULTS}

The 108 surveys underwent the statistical analysis. Basic information regarding participants is presented in the Table 1 . No statistically significant difference between answers to the question about explanation of CT examination objectives and a place of residence, age and education of parents was discovered. However, the correlation between socio-economic conditions and the answer to this question was observed: most answers "yes, sufficiently"- $80 \%$ - were given by parents who declared their condition as good, while the majority of "no" answers - 20\% - were given by parents declaring to live in very good socio-economic conditions. No statistically significant difference between answers to questions about: CT examination aim, explanation of harmfulness of ionizing radiation related to examination and the possibility of consultation with a radiologist and socio-economic 
conditions, a place of residence, age and parents' education was confirmed. The correlation between the question asking if the fact of ionizing radiation including examination was noted down in a health certificate and parents' age in the group with a "no" question was significantly stronger; apart from this no statistically significant difference between this question and socio-economic conditions, a place of residence and parents' education was observed. In the last question of the survey - a substantive one in the a) subsection - "How many times higher dose of radiation does a chest $\mathrm{CT}$ examination with contrast have as compared to a chest X-ray?", the correlation between socio-economic conditions and the percentage rate of correct answers was stated. Most of the correct answers - $28 \%$ - were given by the group declaring "average" conditions, the least of them $-6.35 \%$ - declaring good socio-economic conditions.

An analogical correlation was observed in the case of the question "How many times higher dose of radiation does the abdomen and pelvis CT examination with contrast have as compared to a chest X-ray?". The least correct answers $-3 \%$ - were given by the group declaring good socio-economic conditions. Apart from this no statistically significant differences were observed for the rest of variables in terms of correct and incorrect answers to both questions discussed before. No statistically significant differences in described variables in terms of correct and incorrect answers to the question "How many times higher dose of radiation does a head CT with contrast have as compared to a chest X-ray?" were observed. In the evaluation of all subsections of the question number, 16 majority of answers were incorrect (68-98\%). No correlation between the number of CT examinations conducted for a child and the number of correct answers to substantive questions was observed. No correlation between the number of CT examinations conducted for a child and the fact of noting the examination with the use of ionizing radiation down in a child's health certificate was stated.
The statistical analysis showed that children of parents who declared that the aim of the CT examination was explained to them better underwent more of them.

The authors stated a growing correlation between the number of CT examinations conducted for a child and the number of other examinations - the more often the child underwent the $\mathrm{CT}$ examination, the more other kinds of examinations were conducted (USG, X-ray, MRI, PET, EEG). No correlation between the kind of a referring unit (the type of department) and the percentage rate of correct answers for substantive questions was observed. Only 10 participants $(9.3 \%)$ answered correctly to all 3 sub-sections in the question number 16 .

\section{DISCUSSION}

The use of ionizing radiation in imaging diagnostics requires experience and proper knowledge about a radiation dose related to any kind of radiological procedures. The lack of patients' awareness of the potential risk by which radiological procedures are accompanied in the era of the growing need for imaging diagnostics may cause serious consequences, thus bringing this topic to patients' attention, especially parents, is very important. The results of the survey study trying to assess the awareness of parents whose children undergo CT examination are disappointing. In the substantive question regarding the comparison of radiation doses between respective CT examinations and a chest X-ray, the majority of participants gave wrong answers, with the percentage rate ranging 68-98\%. It could seem that an increase in the number of CT examinations of children would have a positive impact on awareness and knowledge of parents about them. Nevertheless, the results of the study indicate the fact that the number of conducted CT examinations in medical history does not influence the increase in parents' awareness of radiation dose in them. Moreover, no correlation between the number of conducted CT examinations of children and the fact of noting down the examinations in a child's health cer- 
tificate was observed. The one positive result might be the fact that the bigger number of conducted CT examinations leads to an increase number of parents declaring that the aim and harmfulness of the ionizing radiation was more fully explained to them.

In the research by Larson et al. [7], evaluation of the awareness of parents and their willingness to allow to conduct a CT examination of their children after receiving a brochure informing about radiation risk related to this procedure the results was promising. The authors stated that a short leaflet could increase awareness of radiation risk among parents without a denial of the procedure that had been recommended by the referring unit [7]. This is the best proof that parents, after having received upright information, understand much better the fact that CT examination uses ionizing radiation and increases cancer risk. Such awareness may contribute to the decrease of the need for often redundant CT examinations in the pediatric population. It is obviously the medical staff that compare advantages and disadvantages of a procedure and decide. Still, a proper information about possible dangers related to $\mathrm{CT}$ examinations given to a patient or parents of a young patient is crucial, being a part of respect for patient's autonomy.

\section{CONCLUSIONS}

The highest percentage rate: $68-98 \%$ of incorrect answers - was given by the participants in terms of the question regarding a radiation dose administered during a CT examination. At the same time, almost $80 \%$ of caregivers of examined children agreed to talk about radiation risks with an attending physician or radiologist. Age and education of parents, as well as the frequency of examinations, did not have an impact on the caretaker's awareness. Furthermore, a place of residence and sex did not show any significant influence, either. Only $20 \%$ of participants from the group declaring their socio-economic status as very good indicated that the aim of the examination was not explained to them. Moreover, in the other socio-economic groups, the percentage rate was even lower. The results show the lack of proper information about the exposure to ionizing radiation that should be given by physicians. They are responsible for an explanation of not only the aim of the procedure but also all of the risks related to it. The research confirmed a very low awareness of the radiological protection of children among the members of society.

\section{REFERENCES}

1. Brenner D, Elliston C, Hall E, Berdon W. Estimated risks of radiation-induced fatal cancer from pediatric CT. AJR Am J Roentgenol. 2001;176(2):289-96, https://doi.org/10.2214/ajr. 176.2.1760289.

2. Pearce MS, Salotti JA, Little MP, McHugh K, Lee C, Kim KP, et al. Radiation exposure from CT scans in childhood and subsequent risk of leukaemia and brain tumours: A retrospective cohort study. Lancet. 2012;380(9840):499-505, https:// doi.org/10.1016/S0140-6736(12)60815-0.

3. Brenner DJ, Hall EJ. Computed tomography - An increasing source of radiation exposure. N Engl J Med. 2007;357(22): 2277-84, https://doi.org/10.1056/NEJMra072149.

4. Bulas DI, Goske MJ, Applegate KE, Wood BP. Image gently: Why we should talk to parents about CT in children. AJR Am J Roentgenol. 2009;192(5):1176-8, https://doi.org/10. 2214/AJR.08.2218.

5. Mathews JD, Forsythe AV, Brady Z, Butler MW, Goergen SK, Byrnes GB, et al. Cancer risk in 680000 people exposed to computed tomography scans in childhood or adolescence: Data linkage study of 11 million Australians. BMJ. 2013;346:\{2360, https://doi.org/10.1136/bmj.f2360.

6. Ozasa K, Shimizu Y, Suyama A, Kasagi F, Soda M, Grant EJ, et al. Studies of the mortality of atomic bomb survivors, Report 14, 1950-2003: An overview of cancer and noncancer diseases. Radiat Res. 2012;177(3):229-43, https://doi.org/10.1667/RR2629.1.

7. Larson DB, Rader SB, Forman HP, Fenton LZ. Informing parents about $\mathrm{CT}$ radiation exposure in children: It's $\mathrm{OK}$ to tell them. AJR Am J Roentgenol. 2007;189(2):271-5, https:// doi.org/10.2214/AJR.07.2248. 
8. Dillman JR, Strouse PJ, Ellis JH, Cohan RH, Jan SC. Incidence and severity of acute allergic-like reactions to i.v. nonionic iodinated contrast material in children. AJR Am J Roentgenol. 2007;188(6):1643-7, https://doi.org/10.2214/ AJR.06.1328.

9. Leenhouts HP, Chadwick KH. The molecular basis of stochastic and nonstochastic effects. Health Phys. 1989;57 Suppl 1:343-8, https://doi.org/10.1097/00004032-19890700100048 .

10. Little JB. Radiation carcinogenesis. Carcinogenesis. 2000;21(3):397-404, https://doi.org/10.1093/carcin/21.3.397.

11. Mc Laughlin PD, O'Connor OJ, O'Neill SB, Shanahan F, Maher MM. Minimization of radiation exposure due to computed tomography in inflammatory bowel disease. ISRN Gastroenterol. 2012;2012:790279, https://doi. org/10.5402/2012/790279.

12. Wong CS, Huang B, Sin HK, Wong WL, Yiu KL, Chu Yiu Ching T. A questionnaire study assessing local physicians, radiologists and interns' knowledge and practice pertaining to radiation exposure related to radiological imaging. Eur J Radiol. 2012;81(3):e264-8, https://doi.org/10.1016/ j.ejrad.2011.02.022.

13. Keijzers GB, Britton CJ. Doctors' knowledge of patient radiation exposure from diagnostic imaging requested in the emergency department. Med J Aust. 2010;193(8):450-3.
14. Shiralkar S, Rennie A, Snow M, Galland RB, Lewis MH, Gower-Thomas K. Doctors' knowledge of radiation exposure: Questionnaire study. BMJ. 2003;327(7411):371-2, https://doi.org/10.1136/bmj.327.7411.371.

15. Jacob K, Vivian G, Steel JR. X-ray dose training: Are we exposed to enough? Clin Radiol. 2004;59(10):928-34; discussion 926-7, https://doi.org/10.1016/j.crad.2004.04.020.

16. Marin JR, Grudzen CR. Emergency physician radiation risk communication: A role for shared decision-making. Acad Emerg Med. 2014;21(2):211-3, https://doi.org/10.1111/acem. 12313.

17. Baumann BM, Chen EH, Mills AM, Glaspey L, Thompson NM, Jones MK, et al. Patient perceptions of computed tomographic imaging and their understanding of radiation risk and exposure. Ann Emerg Med. 2011;58(1):1-7.e2, https://doi.org/10.1016/j.annemergmed.2010.10.018.

18. Robey TE, Edwards K, Murphy MK. Barriers to computed tomography radiation risk communication in the emergency department: A qualitative analysis of patient and physician perspectives. Acad Emerg Med. 2014;21(2):122-9, https:// doi.org/10.1111/acem.12311. 


\section{Appendix. Questionnaire}

I kindly ask you to complete the following anonymous survey. The results of the research will improve the diagnostic imaging of hospitalized patients in our hospital, and even better adjust to your expectations. They will also develop a scientific basis, therefore we count on your full understanding. On behalf of the team of radiologists, thank you very much for your time.

Please mark the right answer.

Question 1. The type of research that will be conducted in your child:
$\square$ head CT
$\square$ chest CT
$\square$ abdominal CT
pelvic CT
$\square$ CT of another body area
$\square$ whole body CT

Question 2. Was the study planned with intravenous contrast administration?

$$
\text { yes }
$$

$\square$ no

Question 3. Referring unit

$$
\text { Department of Surgery }
$$

Department of Neurology and Infectious Diseases

$\square$ Intensive Care Unit

Question 4. The child was referred to the hospital by:

primary care physician

specialist doctor

$\square$ clinic doctor

emergency department doctor

Question 5. Was your child already hospitalized?

(Please specify how many times)

$\square$ no

$\square$ yes

Question 6. Is this the first CT study of your child?

(Please specify the number)

$\square$ no

$\square$ yes
Question 7. Was your child subjected to other studies in a hospital or outside, if so, how many times:

$\square$ USG:

X-ray images:

$\square$ MRI:

PET:

EEG:

Question 8. Were you explained in a comprehensive manner the purpose of the CT study?

$\square$ yes, thoroughly

$\square$ yes, but incompletely

$\square$ no

Question 9. Were you explained negative effects of ionizing radiation related to the $\mathrm{CT}$ study?

yes, thoroughly

$\square$ yes, but incompletely

$\square$ no

Question 10. Did you have the opportunity to consult with the radiologist?

$\square$ yes

$\square$ yes, but not used

$\square$ no

Question 11. How do you assess your socio-economic conditions?

$\square$ bad

$\square$ average

$\square$ good

$\square$ very good

Question 12. Place of residence

$\square$ village

$\square$ city $<50000$ inhabitants

$\square$ city $50000-500000$ inhabitants

$\square$ city $>500000$ inhabitants

voivodeship city

Question 13. Age of parents

Mother: $\square$ 18-29 years $\square$ 30-39 years

$\square$ 40-49 years $\square>50$ years

Father: $\square$ 18-29 years $\square$ 30-39 years

$\square$ 40-49 years $\square>50$ years 
Question 14. Education

Mother:

$\square$ incomplete primary school

$\square$ lower-secondary

$\square$ basic vocational

upper-secondary

higher

Father

$\square$ incomplete primary school

$\square$ lower-secondary

$\square$ basic vocational

upper-secondary

$\square$ higher

Question 15. Was the fact of ionizing radiation including exami-

nation noted down in your child's health certificate?

$\square$ yes

$\square$ no
Question 16. In your opinion, how many times higher dose of radiation does a CT examination have, compared to a chest $\mathrm{X}$-ray? For comparison:

chest X-ray and chest $\mathrm{CT}$ with contrast

$\square 2 \times$

$\square$ 4x

$\square 40 \times$

chest X-ray and head CT with contrast

$\square 7 \mathrm{x}$

$\square 70 \times$

$100 x$

chest X-ray and abdominal and pelvic $\mathrm{CT}$ with contrast

$\square 3 \times$

$\square 30 \times$

$\square 300 x$

Thank you very much

Radiologists Team

This work is available in Open Access model and licensed under a Creative Commons Attribution-NonCommercial 3.0 Poland License - http://creativecommons.org/ licenses/by-nc/3.0/pl/deed.en. 